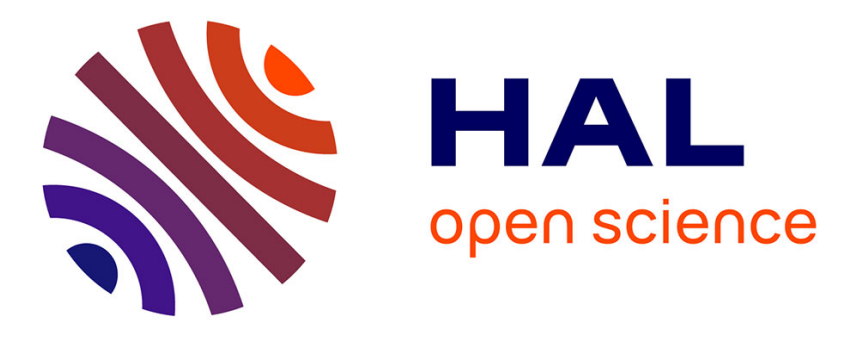

\title{
Delayed-Mode Calibration of Hydrographic Data Obtained from Animal-Borne Satellite Relay Data Loggers
}

Fabien Roquet, Jean-Benoit Charrassin, Stéphane Marchand, Lars Boehme, Michael A. Fedak, Gilles Reverdin, Christophe Guinet

\section{To cite this version:}

Fabien Roquet, Jean-Benoit Charrassin, Stéphane Marchand, Lars Boehme, Michael A. Fedak, et al.. Delayed-Mode Calibration of Hydrographic Data Obtained from Animal-Borne Satellite Relay Data Loggers. Journal of Atmospheric and Oceanic Technology, 2011, 28 (6), pp.787-801. 10.1175/2010JTECHO801.1 . hal-00624609

\section{HAL Id: hal-00624609 \\ https://hal.science/hal-00624609}

Submitted on 3 Nov 2021

HAL is a multi-disciplinary open access archive for the deposit and dissemination of scientific research documents, whether they are published or not. The documents may come from teaching and research institutions in France or abroad, or from public or private research centers.
L'archive ouverte pluridisciplinaire HAL, est destinée au dépôt et à la diffusion de documents scientifiques de niveau recherche, publiés ou non, émanant des établissements d'enseignement et de recherche français ou étrangers, des laboratoires publics ou privés.

\section{(ㄷ)(i)}

Distributed under a Creative Commons Attribution| 4.0 International License 


\title{
Delayed-Mode Calibration of Hydrographic Data Obtained from Animal-Borne Satellite Relay Data Loggers
}

\author{
FAbien Roquet,* JeAn-Benoit Charrassin, And Stephane Marchand \\ LOCEAN/Museum National d'Histoire Naturelle, Paris, France \\ LARS BOEHME AND MiKe FEDAK \\ Sea Mammal Research Unit, Scottish Oceans Institute, Natural Environment \\ Research Council, St. Andrews, United Kingdom \\ GILLES REVERDIN \\ LOCEAN/IPSL, Paris, France \\ CHRISTOPHE GUINET \\ CEBC-CNRS UPR 1934, F-79360, Villiers en Bois, France
}

(Manuscript received 20 May 2010, in final form 8 February 2011)

\begin{abstract}
A delayed-mode calibration procedure is presented to improve the quality of hydrographic data from CTD-Satellite Relay Data Loggers (CTD-SRDL) deployed on elephant seals. This procedure is applied on a dataset obtained with 10 CTD-SRDLs deployed at Kerguelen Islands in 2007. A comparison of CTDSRDLs with a ship-based CTD system is first presented. A pressure-effect correction, linear with pressure, is deduced for both temperature and salinity measurements. An external field effect on the conductivity sensor is also detected, inducing an additional salinity offset. The salinity offset cannot be estimated directly from the ship-based CTD comparisons, because the attachment of the CTD-SRDL on the seal head modifies the magnitude of the external field effect. Two methods are proposed for estimating a posteriori the salinity offset. The first method uses the stable salinity maximum characterizing the Lower Circumpolar Deep Water (LCDW), sampled by seals foraging south of the Southern Antarctic Circumpolar Current Front. Where this approach is not possible, a statistical method of cross-comparison of CTD-SRDLs surface salinity measurements is used over the sluggish Northern Kerguelen Plateau. Accuracies are respectively estimated as $\pm 0.02^{\circ} \mathrm{C}$ for temperature and \pm 0.1 for derived salinity without corrections. The delayed-mode calibration significantly improves the CTD-SRDL data, improving accuracies to $\pm 0.01^{\circ} \mathrm{C}$ and \pm 0.03 , respectively. A better salinity accuracy of \pm 0.02 is achieved when the LCDW method can be used. For CTD-SRDLs where ship-based CTD comparisons are not available, the expected accuracy would be $\pm 0.02^{\circ} \mathrm{C}$ for temperature and \pm 0.04 for the derived salinity.
\end{abstract}

\footnotetext{
* Current affiliation: Department of Earth, Atmospheric and Planetary Sciences, Massachusetts Institute of Technology, Cambridge, Massachusetts.
}

Corresponding author address: Fabien Roquet, Dept. of Earth, Atmospheric and Planetary Sciences, Massachusetts Institute of Technology, Cambridge, MA 02139.

E-mail: roquet@mit.edu

\section{Introduction}

Our understanding of the at-sea behavior and physiology of free-ranging marine animals has been revolutionized in the last decades by the development and deployment of a variety of loggers (see the review of Bost et al. 2009). This new field of biologging was made possible thanks to recent progress in microelectronics, miniaturization, and satellite telemetry. While loggers 
were providing a host of new information for biologists, the idea of gathering oceanographic parameters simultaneously has naturally emerged. A synergy between biologist's efforts to understand the marine life and physical oceanographic studies became possible in the early 2000s with the development of satellite-relay biologging devices incorporating high-accuracy oceanographic sensors (Fig. 1). These Satellite Relay Data Loggers (SRDLs) were developed at the Sea Mammal Research Unit (SMRU), in the United Kingdom, and they can provide fundamental information not only for biologists, but also for oceanographers in the form of vertical profiles of temperature and salinity using a miniaturized conductivitytemperature-depth (CTD) cell (Fedak 2004; Boehme et al. 2009).

Southern elephant seals (Mirounga leonina) are excellent candidates for the deployment of these new loggers. These top predators dive nearly continuously and to great depths (Hindell et al. 1992). Moreover, they undertake long foraging trips each year, exploring large areas of the Southern Ocean. Deploying CTD-SRDLs on elephant seals allowed biologists to better understand the seal foraging strategies in relation to the oceanographic conditions (Biuw et al. 2007; Bailleul et al. 2007) and to explain the differences in population trends among the different colonies around the Southern Ocean (Biuw et al. 2007).

The CTD profiles sampled in the remote Southern Ocean by CTD-SRDLs are of great interest for oceanographers because they complement the ocean observing system efficiently (e.g., Boehme et al. 2008; Costa et al. 2008; Charrassin et al. 2008; Nicholls et al. 2008; Roquet et al. 2009). By combining all CTD-SRDL profiles sampled in the Southern Ocean between 2004 and $2005(n=$ 14 470), Charrassin et al. (2008) demonstrated their great value for describing circumpolar fronts and water mass characteristics, especially under the sea ice. The number of deployed CTD-SRDLs have increased steadily each year, using additional species of seals in a wide variety of deployments sites, like Weddell seals along Antarctica or hooded seals in the North Atlantic. In several sectors of the Southern Ocean, profiles from animal-borne CTDSRDLs are becoming a predominant data source. It is therefore important to develop effective means for calibration, quality control, and postprocessing to avoid biases in climatologies and ocean-state estimates.

There is also a need to assess the accuracy of CTDSRDL hydrographic measurements under actual field conditions. CTD-SRDLs are designed to achieve accuracies similar to those of Argo floats, that is, on the order of $\pm 0.01^{\circ} \mathrm{C}$ in temperature and \pm 0.01 in salinity, requiring better than $0.01 \mathrm{mS} \mathrm{cm}^{-1}$ accuracy in conductivity. Based on checks in the calibration laboratory at Valeport Ltd. (Devon, United Kingdom), Boehme et al. (2009) reported

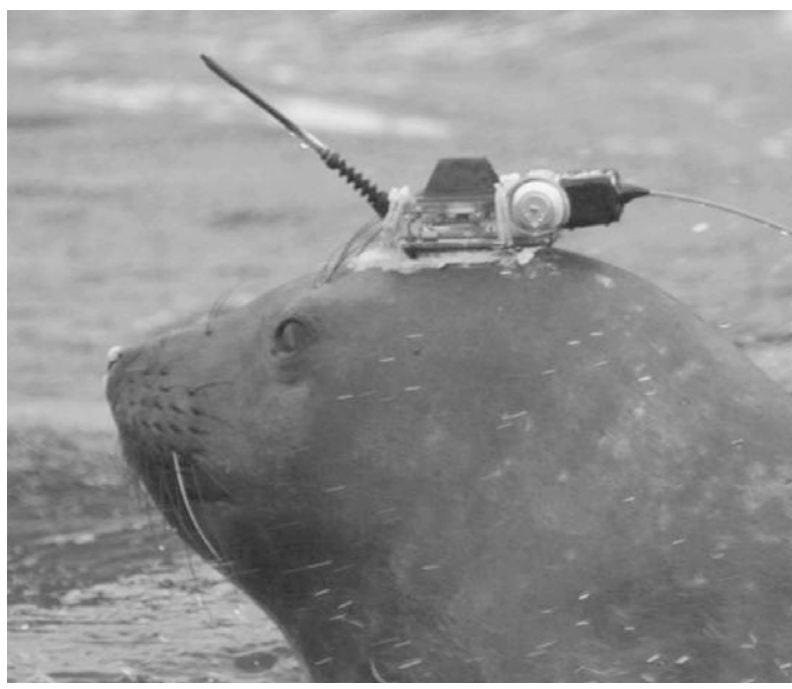

FIG. 1. CTD-SRDL deployed on a southern elephant seal. An additional VHF tracking device is attached on the back.

accuracies (standard deviation) of $\pm 0.005^{\circ} \mathrm{C}$ in temperature and \pm 0.02 in the derived salinity.

These accuracies correspond to the ideal case of an undisturbed environment. However, several sources of error are not accounted in predeployment calibration checks at the laboratory. These include pressure effects on sensors that are not calibrated in the laboratory. Another known issue is the external field effect on conductivity sensors with inductive coils (Fougere 2000; Wong et al. 2003; Hooker and Boyd 2003). Indeed, these conductivity sensors produce an external magnetic field, which can interfere with nearby objects. In practice, the magnitude of the external field effect depends on how the CTD-SRDL has been attached to the animal, and on the presence of objects around CTD-SRDLs. Boehme et al. (2009) presented tank tests, showing that any object closer than $10 \mathrm{~cm}$ can change salinity up to 0.5 , with typical deviations around 0.1 . The magnitude of the external field effect offset remains constant during the entire deployment period, but must be estimated a posteriori.

After briefly reviewing technical specifications of CTD-SRDLs, we describe the delayed-mode calibration of 10 CTD-SRDLs deployed on elephant seals in Kerguelen Islands in 2007. This dataset comprises a total of 3045 profiles (Fig. 2, Table 1), mainly sampled over the Kerguelen Plateau and in the western AustralianAntarctic Basin (for a description of the area, see, e.g., Roquet et al. 2009). The calibration is divided in two steps. First, at-sea experiments were carried out in the Mediterranean Sea before CTD-SRDLs were deployed on the seals' heads, so that CTD-SRDLs could be compared to measurements from a ship-based CTD system. 


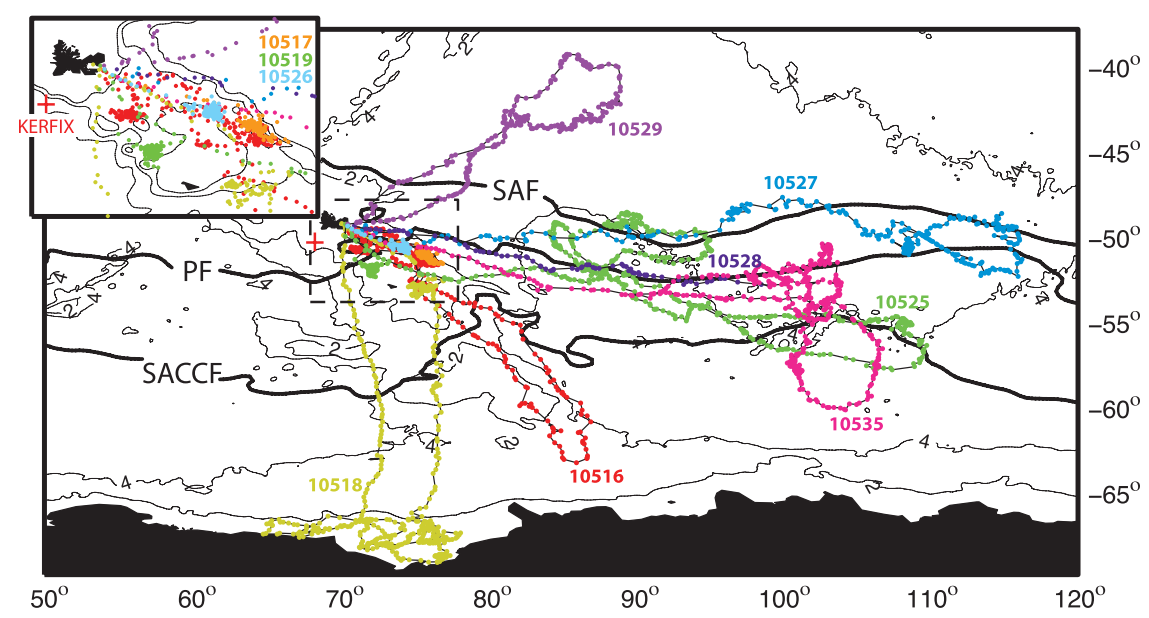

FIG. 2. Spatial distribution of profiles collected by 10 CTD-SRDLs deployed in 2007 on the Kerguelen Islands. Climatological position of main ACC fronts as determined by selected isolines of the mean dynamic topography (Rio and Hernandez 2004) are superimposed (we used isolines $-1,-0.65$, and $-0.25 \mathrm{~m}$ for the Southern ACC, polar, and Subantarctic fronts, respectively). The position of station KERFIX is indicated with a red cross. The inset shows a zoom on the area of the Northern Kerguelen Plateau.

These comparisons were used to correct pressure-induced linear biases on both temperature and salinity measurements. A salinity offset correction is then carried out using delayed-mode methods.

\section{Technical description of CTD-SRDLs}

A thorough technical description of CTD-SRDLs can be found in Boehme et al. (2009), which we briefly summarize here (see also Fedak et al. 2002; Fedak 2004). CTD-SRDLs have been designed as miniaturized platforms to record behavioral data and $\log$ in situ CTD profiles. They can be deployed on a range of marine mammals (e.g., Lydersen et al. 2002; Boehme et al. 2008; Nicholls et al. 2008; Roquet et al. 2009). The devices contain a Platform Terminal Transmitter (PTT) to transmit compressed data through the Argos satellite system (Argos 2011). A microcontroller coordinates sensor data acquisition, data processing, and transmission (Boehme et al. 2009).

The specifications of the miniaturized CTD (Valeport, Ltd., Totnes, United Kingdom) result from a trade-off between the need for miniaturization, energy consumption, stability, and sensor performance. The pressure measurements are made by a Keller series PA7 piezoresistive pressure transducer (Keller AG, Winterthur,

TABLE 1. Basic information on the CTD-SRDLs used within this study based on their performance during their deployment in the Southern Ocean on southern elephant seals.

\begin{tabular}{|c|c|c|c|c|c|c|c|c|}
\hline SRDL & $\begin{array}{l}\text { No. of } \\
\text { profiles }\end{array}$ & Starting date & $\begin{array}{c}\text { Travel } \\
\text { duration (days) }\end{array}$ & $\begin{array}{c}\text { No. of } \\
\text { profiles per day }\end{array}$ & $\begin{array}{c}\text { Travel } \\
\text { distance }(\mathrm{km})\end{array}$ & $\begin{array}{l}\text { Deepest depth } \\
\text { (m) }\end{array}$ & $\begin{array}{c}\text { Mean depth } \\
(\mathrm{m})\end{array}$ & $\begin{array}{c}\text { Software } \\
\text { version }\end{array}$ \\
\hline 10516 & 382 & 29 Dec 2006 & 148 & 2.58 & 8808 & 1022 & 476 & $06 \mathrm{~B}$ \\
\hline 10517 & 192 & 31 Dec 2006 & 76 & 2.52 & 2998 & 1098 & 502 & 06B \\
\hline 10518 & 546 & 31 Dec 2006 & 179 & 3.04 & 9465 & 1452 & 278 & 06B \\
\hline 10519 & 162 & 4 Jan 2007 & 79 & 2.05 & 2492 & 810 & 671 & 06B \\
\hline 10525 & 512 & 7 Jan 2007 & 189 & 2.70 & 10139 & 1176 & 595 & 06B \\
\hline 10526 & 128 & 29 Dec 2006 & 49 & 2.60 & 1796 & 742 & 527 & 06B \\
\hline 10527 & 264 & $25 \mathrm{Jul} 2007$ & 179 & 2.05 & 7829 & 1472 & 796 & KER_07A \\
\hline 10528 & 77 & 29 May 2007 & 29 & 2.58 & 2195 & 898 & 575 & KER_07A \\
\hline 10529 & 77 & 29 May 2007 & 29 & 2.58 & 2195 & 898 & 575 & KER_07A \\
\hline 10535 & 490 & 23 May 2007 & 193 & 2.72 & 10238 & 1196 & 661 & KER_07A \\
\hline 10536 & \multicolumn{7}{|c|}{ Stopped emitting prematurely } & KER_07A \\
\hline 10537 & \multicolumn{7}{|c|}{ Stopped emitting prematurely } & KER_07A \\
\hline Mean & 305 & & 125 & 2.51 & 6204 & 1107 & 614 & \\
\hline Std dev & 170 & & 62 & 0.31 & 3518 & 247 & 106 & \\
\hline Sum & 3045 & & 1249 & 25.1 & 62046 & & & \\
\hline
\end{tabular}


Switzerland) with a given accuracy of better than $1 \%$ of the full-scale reading ( \pm 20 dbar at $2000 \mathrm{dbar})$. However, laboratory experiments have shown a performance of better than $0.25 \%$ of the actual reading (Boehme et al. 2009). The temperature probe is a fast-response Platinum Resistance Thermometer (PRT) made by Valeport (range from $-5^{\circ}$ to $+35^{\circ} \mathrm{C}$, accuracy from $\pm 0.005^{\circ} \mathrm{C}$, and time constant of $0.7 \mathrm{~s}$ ) and an inductive conductivity sensor by Valeport (range from 0 to $80 \mathrm{mS} \mathrm{cm}^{-1}$, accuracy of better than $\pm 0.01 \mathrm{mS} \mathrm{cm}^{-1}$ ).

Since mid-2006, the conductivity sensor is contained within pressure housing in titanium and polyurethane. The use of pressure housing improved the sensor stability significantly, minimizing deformations induced by pressure changes. Miniaturized CTD units are built at Valeport and then integrated in the SRDL platform at SMRU. Assembled CTD-SRDLs are then returned to Valeport for calibration. These calibrations have been validated independently at the calibration laboratory of Service Hydrographique et Oceanographique de la Marine (Brest, France) and at the Naval Postgraduate School (Monterey, California).

Long-term drifts of sensors are not thought to be a major problem here, because deployment time is rather short (less than 8 months), the technologies used in CTDSRDLs should be robust against such drifts, and, finally, the continuous movement of the animals combined with a relatively slow growth of fouling organisms in polar seas.

While at sea, elephant seals dive frequently, and spend more than $90 \%$ of their time underwater. It is during their ascent phase that CTD data are logged. A procedure is programmed into the microcontroller of the CTDSRDL to sample the deepest dives in each 6-h time block. A maximum of four profiles could be theoretically transmitted daily. In practice, transmission constraints lead to an average of 2.5 profiles per day that are received through the Argos system for our setup and species, allowing the sampling of quasi-synoptic large-scale sections of major interest to describe fronts (Roquet et al. 2009) as well as their variability (Boehme et al. 2008). In addition, all of the data logged during each dive cannot be transmitted, because of the limited Argos bandwidth and the limited time that seals spend at the surface (less than $10 \%$ of their time).

The CTD-SRDL software provides for user-selected data compression with flexible control of the composition of the data message and the resolution with which data are sent. Data for 18 or 20 depth levels are chosen that best represent the particular upcast on the basis of a set of preselected depths and another set of depths chosen by a broken-stick method to provide the important inflection points in the profiles. Two different versions of the software were used (for definitions, see
Table 1). The KER_06B configuration selects 20 pressure levels based on a broken-stick method applied to temperature. The CTD profile is then compressed by coding temperature and conductivity into 8 bits. Thus, for a profile with a temperature range of $3^{\circ} \mathrm{C}$ and a conductivity range of $1 \mathrm{mS} \mathrm{cm}^{-1}$ (which is typical in polar regions), the resolution is $0.012^{\circ} \mathrm{C}$ and $0.004 \mathrm{mS} \mathrm{cm}{ }^{-1}$ in conductivity, respectively. Pressures are coded with 10 bits, giving a 1-dbar resolution for a 1000-dbar profile. Salinity is then calculated using the compressed data points when the profiles are received and decoded at SMRU.

The KER_07A configuration improves the temperature resolution to $0.006^{\circ} \mathrm{C}$ by using 9 bits to encode temperature. Salinity was computed onboard the tags from temperature and conductivity measurements before compression and was sent using 8 bits, providing a typical resolution of 0.004 . The compressed CTD profile was encoded into two distinct 32-bytes Argos packets sent when a wet-dry sensor detected that the antenna of the CTD-SRDL was above the surface. Some CTD profiles (about 30\% ) contain 10 data points (the first packet only) instead of 18, if the second packet transmission fails.

Locations are estimated by the Argos system using the Doppler shift in frequency of the received packets by a satellite. However, because of the limited number of transmitted and received packets a proportion of estimated locations are of low accuracy. Vincent et al. (2002) have studied accuracy of each of the location classes using four gray seals fitted with Argos transmitter held in captivity in an outdoor tank. By a rule-of-thumb based on their statistics, we estimate that the 95th (68th) percentile of elephant seals location accuracy is of $\pm 5(1.5) \mathrm{km}$.

CTD-SRDLs are attached to the fur on the seals' heads using quick-setting epoxy, which falls off when the seals undergo their annual molt the following year. To help the recovery of CTD-SRDLs on the field, a VHF transmitter is often glued to the rear of the CTD-SRDL (see Fig. 1). More recently, a fluorometer has also been integrated into CTD-SRDLs, and an oxygen sensor is under development. Additional devices put around the CTD-SRDL do not change the approach presented in this study to calibrate hydrographic sensors, because the only effect they could induce is an additional external field effect which will be taken into account during the salinity offset correction.

\section{Comparison with a ship-based CTD system}

\section{a. At-sea experiment}

In November 2006, an at-sea experiment was conducted in the Mediterranean Sea on the research vessel Tethys, during the BOUSSOLE hydrographic cruise 
(see Antoine et al. 2006). Twelve CTD-SRDLs were attached with the antenna looking upward to the frame of a ship-based CTD, a SBE25 CTD. The SBE25 CTD is calibrated by SeaBird and has an accuracy of $\pm 0.5 \mathrm{dbar}$ in pressure, $\pm 0.0025^{\circ} \mathrm{C}$ in temperature, and \pm 0.005 $\mathrm{mS} \mathrm{cm}{ }^{-1}$ in conductivity. CTD-SRDLs were set into a calibration mode in which they sample every second, and this high-resolution profile was then downloaded after each cast. The vertical speed of the ship-based CTD frame was set to $1 \mathrm{~m} \mathrm{~s}^{-1}$, which is a speed comparable to the typical seal ascent speed $\left(1-2 \mathrm{~m} \mathrm{~s}^{-1}\right)$. Seven casts to 400-m depth were performed and the upcast for each CTD-SRDL compared to the measurements of the SBE25 CTD.

The procedure used to compare CTD-SRDL profiles to the SBE25 was as follows: CTD-SRDL profiles were first resampled into 1-dbar bins. Because CTD-SRDLs were not attached at the same height as the SBE25, a synchronization of hydrographic measurements was performed. CTD-SRDL pressure measurements were adjusted to the SBE25 to synchronize small "wiggles" observed in the conductivity measurements. Conductivity is suitable for synchronization because conductivity sensors have virtually no time lag. Pressure adjustments were within the error bars specified by Valeport (less than 5-dbar deviation at $1000 \mathrm{~m}$ ). Salinity profiles were then calculated using the practical salinity scale (pss-78, see Fofonoff and Millard 1983). Synchronized profiles were averaged over 10 -m bins. Only bins with an ensemble standard deviation of less than 0.01 in temperature and salinity were used.

The difference between CTD-SRDL and SBE25 measurements were then pooled together for each CTDSRDL, and linear fits over pressure were determined for both temperature $(T)$ and salinity $(S)$ using

$$
T_{m}-T_{r}=\alpha_{t} P_{r}+\beta_{t}+\varepsilon_{t}
$$

and

$$
S_{m}-S_{r}=\alpha_{s} P_{r}+\beta_{s}+\varepsilon_{s}
$$

with temperature $T_{m}$ and salinity $S_{m}$ from CTD-SRDL data; pressure $P_{r}$, temperature $T_{r}$, and salinity $S_{r}$ from the SBE25 data; $\alpha_{t}, \beta_{t}, \alpha_{s}$, and $\beta_{s}$ the coefficients of linear fits; and $\varepsilon_{t}$ and $\varepsilon_{s}$ the residuals of the null average. The fit is done on derived salinity measurements instead of conductivity measurements, because salinity is the final product of interest. Also, temperature and conductivity errors are correlated, and partly cancel each other out in the derived salinity.

A typical profile comparison between CTD-SRDL 10516 and the SBE25 CTD before binning is presented in Fig. 3. The general shapes of the temperature and salinity profiles compare well between the two instruments, and small fluctuations of about $0.01^{\circ} \mathrm{C}$ and 0.01 are consistently detected by the CTD-SRDL within the $1-\mathrm{Hz}$ sampling rate, demonstrating the fast-response ability of CTD-SRDL sensors. However, nonnegligible differences in temperature and salinity are visible. These biases are consistently observed during the seven dives that are available for CTD-SRDL 10516, as can be seen in Fig. 4. The linear fit in temperature shows a slight decrease with pressure of $-0.026^{\circ} \mathrm{C}$ over $1000 \mathrm{~m}$. The linear fit in salinity is offset by about -0.05 at $200-\mathrm{m}$ depth with a variation with pressure of 0.050 over $1000 \mathrm{~m}$. The variations among dives is very small, as can be seen from the standard error of the linear fits being as low as $0.004^{\circ} \mathrm{C}$ and 0.002 , respectively.

In the depth range between 60-m depth and the surface, rapid changes in temperature of the water (more than $5^{\circ} \mathrm{C}$ in a $20-\mathrm{m}$ deep thermocline layer) induced larger errors in both temperature and derived salinity. This is probably due to a thermal mass effect, that is, a slower response time of the CTD-SRDL resulting from core temperature of the device affecting measurements. Temperature differences of up to $0.05^{\circ} \mathrm{C}$ were observed near the surface leading to salinity spikes and significant deviations between the readings of the SBE25 and the CTD-SRDL. While in these circumstances the temperature accuracy remains suitable for many oceanographic applications in the surface mixed layer, this issue certainly should be recognized as a potential problem, especially for the derived salinity. A correction of these effects is not attempted in this paper. Large vertical gradients are not found in polar regions where most CTDSRDLs were deployed; thus, the thermal mass effect should not be a major issue there. However, one must be aware that CTD-SRDL accuracy is reduced across strong thermoclines.

Statistics on temperature and salinity biases for all CTD-SRDLs are reported in Table 2, including the root-mean-square (rms) of the difference, and the slope, surface offset, and standard error of both linear fits. During ship-based CTD comparisons, the slopes of the temperature linear fit $\alpha_{t}$ were either positive or negative, with a mean absolute value of $0.023^{\circ} \mathrm{C} \mathrm{km}^{-1}$. They rarely exceeded $0.03^{\circ} \mathrm{C} \mathrm{km}^{-1}$, with a worst case of $0.053^{\circ} \mathrm{C} \mathrm{km}^{-1}$ for CTD-SRDL 10527. The surface offsets $\beta_{t}$ were generally slightly positive around $0.015^{\circ} \mathrm{C}$. The salinity biases all showed a negative offset with an average of -0.09 . The slopes of the salinity fits $\alpha_{s}$ were tag dependent, with an average of $0.021 \mathrm{~km}^{-1}$, ranging between negligible values lower than $0.01 \mathrm{~km}^{-1}$ to a worst case of $0.05 \mathrm{~km}^{-1}$ for CTD-SRDLs 10527 and 10526. RMS provides an estimate of the true accuracy before correction, which is of the order of $0.02^{\circ} \mathrm{C}$ for temperature 

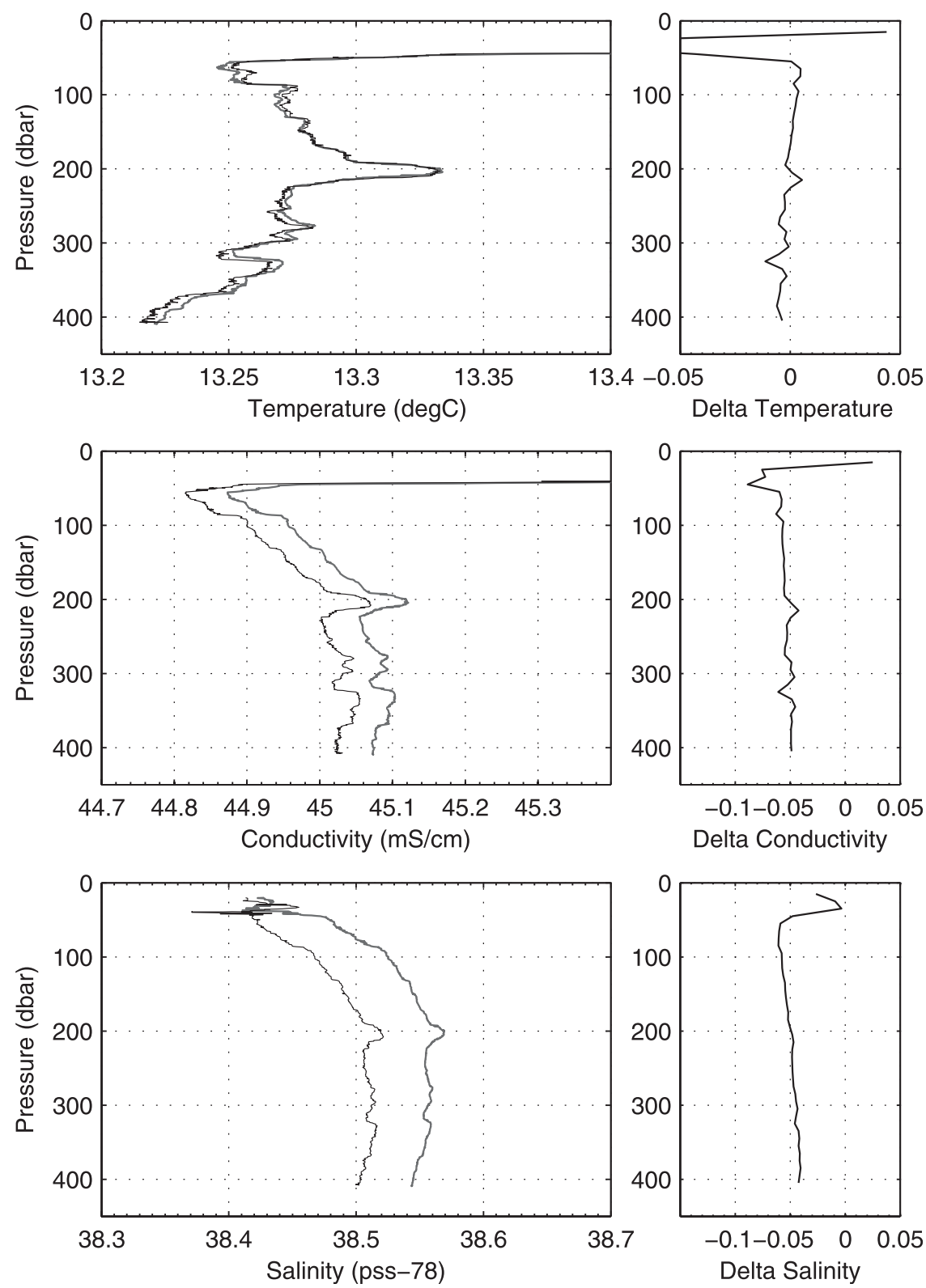

FIG. 3. Vertical profiles of (top) temperature, (middle) conductivity, and (bottom) salinity sampled by CTD-SRDL 10516 (black) and the ship-based CTD (gray) during the same cast. (right) Differences between the CTD-SRDL and the SBE25.

and 0.1 for salinity measurements. A simple linear correction can significantly reduce errors, leading to standard errors of only $0.003^{\circ} \mathrm{C}$ and 0.003 , respectively. This demonstrates that it is theoretically possible to achieve accuracies better than $0.01^{\circ} \mathrm{C}$ and 0.01 for CTD-SRDL measurements, depending on our ability to estimate and correct the observed biases.

\section{b. Pressure-effect correction}

Using the ship-based CTD comparisons, a pressureeffect correction could be deduced to correct hydrographic data collected during the deployment time on elephant seals. The pressure-effect correction for temperature was straightforward:

$$
T_{\mathrm{cor}}=T-\alpha_{t} P-\beta_{t}
$$

where $P$ is the pressure, and $\alpha_{t}$ and $\beta_{t}$ are the same as in Table 2 .

The procedure to correct salinity profiles was more complicated, because the salinity biases were due to a combination of the pressure effect with the external 

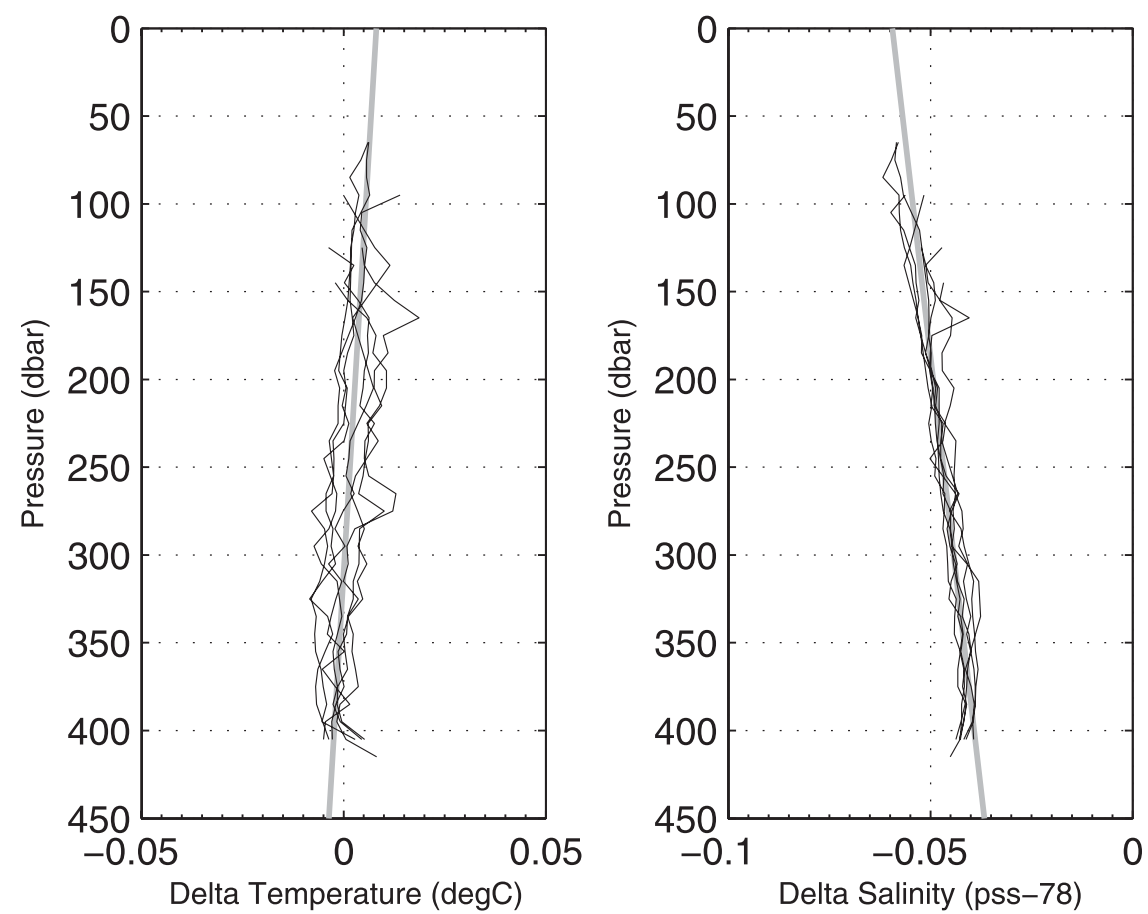

FIG. 4. Differences between the CTD-SRDL and the SBE25 of the 7 bias profiles of (left) temperature and (right) salinity superimposed with the linear fit (thick gray lines) for CTD-SRDL 10516.

field effect. As for temperature, the model used to correct salinity measurements was linear with pressure,

$$
S_{\text {cor }}=S-A_{s} P-B_{s}
$$

but the coefficients $A_{s}$ and $B_{s}$ were not directly those obtained by the linear fit of the difference with the shipbased CTD system. The pressure effect on salinity was again modeled as being linear with pressure; however, the external field effect induced an additional salinity offset (see appendix A). Because the magnitude of the external field effect was modified when the CTD-SRDLs were attached over the seals' heads, the salinity offset $B_{s}$ was likely different during the at-sea experiment and during the deployment time.

The pressure-effect correction on salinity consisted in removing the slope contribution $A_{s} P$, while the salinity offset correction (removal of $B_{s}$ ) was performed separately using delayed-mode approaches, which will be presented later. The slope coefficient $A_{s}$ was estimated

TABLE 2. Statistics relative to temperature and salinity biases measured during at-sea experiments: depth mean and standard deviation of bias; slope $\alpha$; offset at origin $\beta$; and standard error of the linear fit. Slopes are given in unit per kilometer.

\begin{tabular}{|c|c|c|c|c|c|c|c|c|}
\hline \multirow[b]{2}{*}{ SRDL No. } & \multicolumn{4}{|c|}{ Temperature $\left({ }^{\circ} \mathrm{C}\right)$} & \multicolumn{4}{|c|}{ Salinity (pss-78) } \\
\hline & $\mathrm{Rms}$ & $\alpha_{t}$ & $\beta_{t}$ & Standard error & $\mathrm{rms}$ & $\alpha_{s}$ & $\beta_{s}$ & Standard error \\
\hline 10516 & 0.004 & -0.026 & 0.008 & 0.004 & 0.046 & 0.050 & -0.060 & 0.002 \\
\hline 10517 & 0.004 & -0.035 & 0.011 & 0.003 & 0.066 & 0.047 & -0.079 & 0.003 \\
\hline 10518 & 0.014 & 0.026 & 0.007 & 0.002 & 0.126 & -0.009 & -0.124 & 0.002 \\
\hline 10519 & 0.010 & -0.021 & 0.015 & 0.002 & 0.097 & 0.033 & -0.106 & 0.003 \\
\hline 10525 & 0.004 & 0.020 & 0.015 & 0.004 & 0.121 & 0.005 & -0.122 & 0.003 \\
\hline 10526 & 0.028 & -0.030 & 0.010 & 0.003 & 0.087 & 0.050 & -0.101 & 0.002 \\
\hline 10527 & 0.040 & 0.053 & 0.026 & 0.003 & 0.082 & 0.006 & -0.083 & 0.004 \\
\hline 10528 & 0.027 & 0.013 & 0.024 & 0.003 & 0.066 & 0.003 & -0.067 & 0.003 \\
\hline 10529 & 0.019 & 0.017 & 0.014 & 0.003 & 0.116 & -0.008 & -0.114 & 0.004 \\
\hline 10535 & 0.012 & -0.008 & 0.014 & 0.003 & 0.102 & 0.028 & -0.109 & 0.002 \\
\hline 10536 & 0.028 & 0.025 & 0.021 & 0.003 & 0.094 & 0.010 & -0.091 & 0.003 \\
\hline 10537 & 0.016 & 0.003 & 0.015 & 0.003 & 0.088 & 0.009 & -0.090 & 0.002 \\
\hline Mean & 0.016 & 0.023 & 0.015 & 0.003 & 0.091 & 0.021 & -0.095 & 0.003 \\
\hline
\end{tabular}


(a)

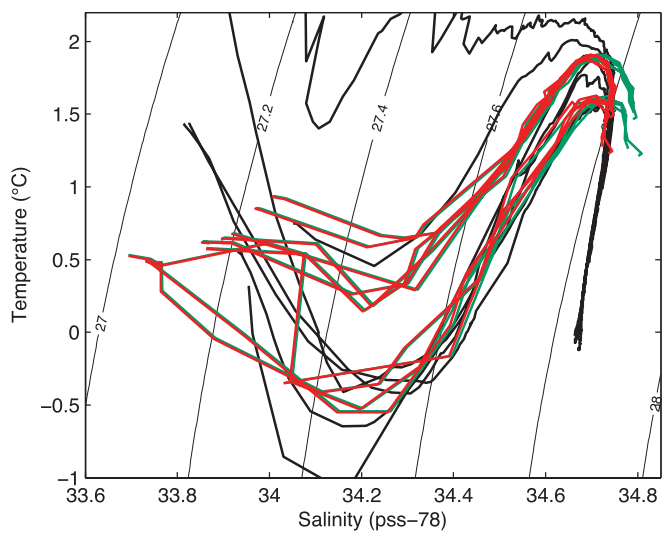

(b)

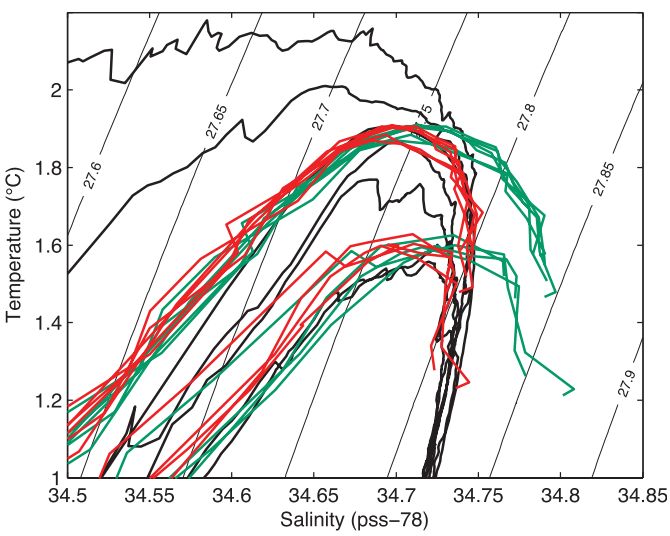

FIG. 5. Comparison between several selected profiles of the CTD-SRDL 10516 and historical profiles. Selected CTD-SRDL profiles are presented with no correction (green) and after the pressure-effect correction (red). Close historical profiles with comparable $T / S$ properties are overlaid (black). (a) The $T / S$ curves and (b) zoomed on their deep part. The pressure-effect correction allows a much better overlapping with historical $T / S$ diagrams at depth.

using ship-based CTD comparisons in a way that accounted for nonlinearities of the relation between conductivity and salinity,

$$
A_{s}=\alpha_{t}\left(\frac{\partial S}{\partial T}\right)_{C}+\alpha_{c}\left(\frac{\partial S}{\partial C}\right)_{T} .
$$

Partial derivatives of salinity were derived from the practical salinity scale definition (Fofonoff and Millard 1983). Because they are weakly dependent on pressure, these derivatives were taken directly at the surface; $\alpha_{c}$ corresponds to the pressure-effect slope on conductivity measurements,

$$
\alpha_{c}=\frac{\left[\alpha_{s}-\alpha_{t} \overline{(\partial S / \partial T)_{C}}\right]}{\overline{(\partial S / \partial C)_{T}}},
$$

where the overline - designates an average value during ship-based CTD comparisons. In the Mediterranean Sea, $\bar{T} \simeq 13^{\circ} \mathrm{C}$ and $\bar{C} \simeq 45 \mathrm{mS} \mathrm{cm}^{-1}$, and thus $\overline{(\partial S / \partial T)_{C}} \simeq$ $-1.00^{\circ} \mathrm{C}^{-1}$ and $\overline{(\partial S / \partial C)_{T}} \simeq 0.95\left(\mathrm{mS} \mathrm{cm}^{-1}\right)^{-1}$.

Several temperature-salinity $(T / S)$ curves of CTDSRDL 10516 are presented in Fig. 5, both before and after the pressure-effect correction (including temperature and salinity slope corrections). Nearby historical profiles are superimposed. The deep part of $T / S$ curves (rightmost part in Fig. 5) shows a maximum in temperature followed by a deeper maximum in salinity. Before the pressure-effect correction, the curvature of the deep part of seal $T / S$ curves was too weak, yielding abnormally saline water mass at depth and the absence of the characteristic salinity maximum. The pressure-effect correction improved the curvature of the deep part of seal $T / S$ curves, allowing a better match between deep parts of seal and historical $T / S$ curves, which would otherwise be impossible to achieve. This $T / S$ curve comparison is used again later to estimate the salinity offset $B_{s}$ (using the LCDW method), which happened to be simply 0 in the case of CTD-SRDL 10516.

\section{Salinity offset correction}

After applying pressure-effect corrections for temperature and salinity on all CTD-SRDLs, the salinity offset is now addressed. The salinity offset $B_{s}$ results from a combination of both the pressure effect and the external field effect, although the latter effect is likely to account for most of its magnitude. Because ship-based CTD comparisons could not be used to estimate $B_{s}$, delayed-mode approaches are now presented.

Although delayed-mode methods of salinity calibration have been developed for Argo float data, such as the method of Wong et al. (2003) (see also Boehme and Send 2005), they could not be used here to estimate the salinity offset for CTD-SRDL data. These methods are based on the existence of strong correlations between temperature and salinity at depth to estimate a salinity correction using a least squares method. However, they require a dense and recent database of historical profiles, yet the southern part of the Southern Ocean remains one of the most poorly sampled regions of the World Ocean. They also require sufficiently deep profiles (if possible, more than $1500 \mathrm{~m}$ ), but seal profiles are mostly less than $1000 \mathrm{~m}$ deep.

Two delayed-mode methods were developed to estimate CTD-SRDL salinity offsets; the first one was efficient only when seals foraged sufficiently far south, and 
the second one was used for seals that crossed the Northern Kerguelen Plateau.

\section{a. The Lower Circumpolar Deep Water method}

This method relies on the existence of a very stable feature in the Southern Ocean, namely, a deep salinity maximum originating from the input of North Atlantic Deep Water into the Antarctic Circumpolar Current (ACC), and forming the core of the Lower Circumpolar Deep Water (LCDW; see e.g., Orsi et al. 1995). The LCDW is upwelled close to the surface in the southern part of the Southern Ocean as part of the meridional overturning circulation, and it provides a very stable absolute reference to estimate CTD-SRDL salinity offsets.

The salinity maximum is generally found in the salinity range of 34.7-34.8, and is shallower than $1000 \mathrm{~m}$ in the circumpolar area between the Southern Antarctic Circumpolar Current Front (SACCF; e.g., Orsi et al. 1995) and the Antarctic continental margin, including the three subpolar gyres (Weddell, Australian-Antarctic, and Ross), allowing the LCDW method to be used for seal data there. At the longitude of the Kerguelen Plateau, it corresponds to the region south of $59^{\circ} \mathrm{S}$ (Fig. 2; see also Park et al. 2009).

Roquet et al. (2009) calibrated a 2004 seal dataset using a statistical comparison of salinity maximum values with a hydrographic atlas. To obtain a better estimate, we preferred to compare seal $T / S$ curves directly with nearby historical profiles here. In Fig. 5, we present such a comparison for the CTD-SRDL 10516, in the region south of the SACCF (around $60^{\circ} \mathrm{S}, 85^{\circ} \mathrm{E}$; see Fig. 2). The deep part of $T / S$ curves (rightmost part in Fig. 5a, expanded in Fig. 5b) shows two local maxima-a maximum in temperature followed by a deeper maximum in salinity. This latter maximum in salinity characterizes the LCDW used here as the reference. The good match between CTDSRDL and nearby historical profiles (after the pressureeffect correction) means that in this case, there was no measurable salinity offset.

Using similar comparisons of $T / S$ curves, offsets of the 2 CTD-SRDLs 10518 and 10535 were estimated as -0.01 and -0.07 , respectively. Because the LCDW salinity maximum is stable through time and space, the LCDW method provides an accuracy of the salinity offset estimate of better than \pm 0.02 when seals forage sufficiently far south. The other seals did not forage south of the SACCF, so their salinity measurements could not be corrected using the LCDW method.

\section{b. A statistical cross-comparison method}

The second method of salinity offset estimation used the possibility of cross-comparing salinity measurements of the different CTD-SRDLs. While either leaving or returning to the Kerguelen Islands, elephant seals most often crossed the Northern Kerguelen Plateau (Fig. 2), an extended plateau that is shallower than $1000 \mathrm{~m}$. Some individuals remained and foraged there during several weeks while others just crossed over. This turned out to be an opportunity for us to calibrate the whole seal dataset. Indeed, the circulation over the Northern Kerguelen Plateau is sluggish and highly controlled by the complex bathymetry, and displays relatively weak temporal variability of hydrographic properties. In particular, the surface salinity over the Northern Kerguelen Plateau is relatively homogeneous, and counterintuitively the lowest variability is found in the surface mixed layer (top $150 \mathrm{~m}$ ), as observed during the KEOPS hydrographic cruise (see Park et al. 2008).

This can be seen from the 4-yr monthly time series at station KERFIX (Park et al. 1998), which is situated just southwest of the Kerguelen Islands over the Northern Kerguelen Plateau (Fig. 6, location shown in Fig. 2). Surface salinity changes over a month generally range between -0.02 and +0.03 (Fig. 6c). The changes are slightly negative, on average, from January to July. The largest monthly changes in salinity are observed between August and October, probably resulting from the deepening of the surface mixed layer during the early winter. The standard deviation of 1-month lagged salinity differences is only 0.01 at surface, which is a value that is much lower than everywhere else below it $(0.09$ at $250 \mathrm{~m}$, and 0.04 at $500 \mathrm{~m}$ ). Surface salinity comparisons thus have a better potential to provide salinity offset estimates over the Northern Kerguelen Plateau than deeper water masses. Surface salinities have the additional advantage of being defined at a depth that is independent of the temperature and being available for every seal profile.

A statistical cross-comparison method has been developed to minimize the difference in surface salinity between nearby profiles taken in an area of relatively low temporal and spatial variability, namely, the Northern Kerguelen Plateau. This statistical cross-comparison method is derived from the weighted least squares minimization algorithm. It generalizes the intercomparison method of Durand and Reverdin (2005). Although used only for the specific case of cross-comparing surface salinity measurements of different CTD-SRDLs over the Northern Kerguelen Plateau, the statistical method is a generic framework that could theoretically be used to cross-compare properties of other water masses. Details of the statistical method are provided in appendix B.

The choice of the statistical model of the covariance between two observations is central to the estimation, as for any objective analysis. The covariance is Gaussian, using the following values for correlation radii: $\lambda_{x}=1^{\circ}$ longitude and $\lambda=0.5^{\circ}$ latitude, equivalent to a $50-\mathrm{km}$ isotropic 
(a) Salinity timeseries, station KERFIX

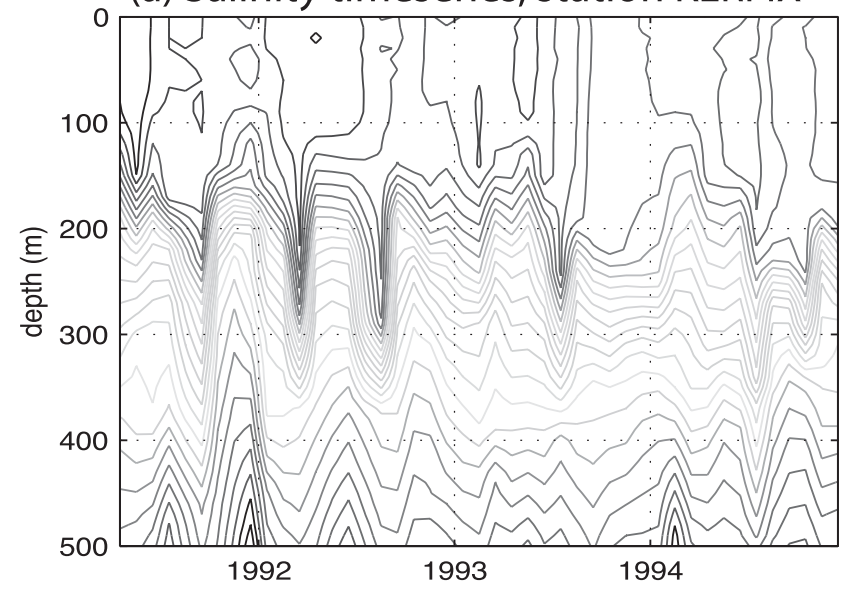

(b) STD

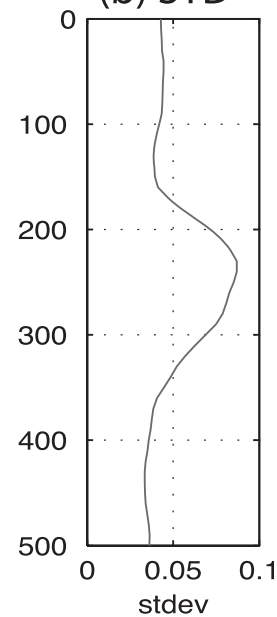

(c) Monthly variation of surface salinity

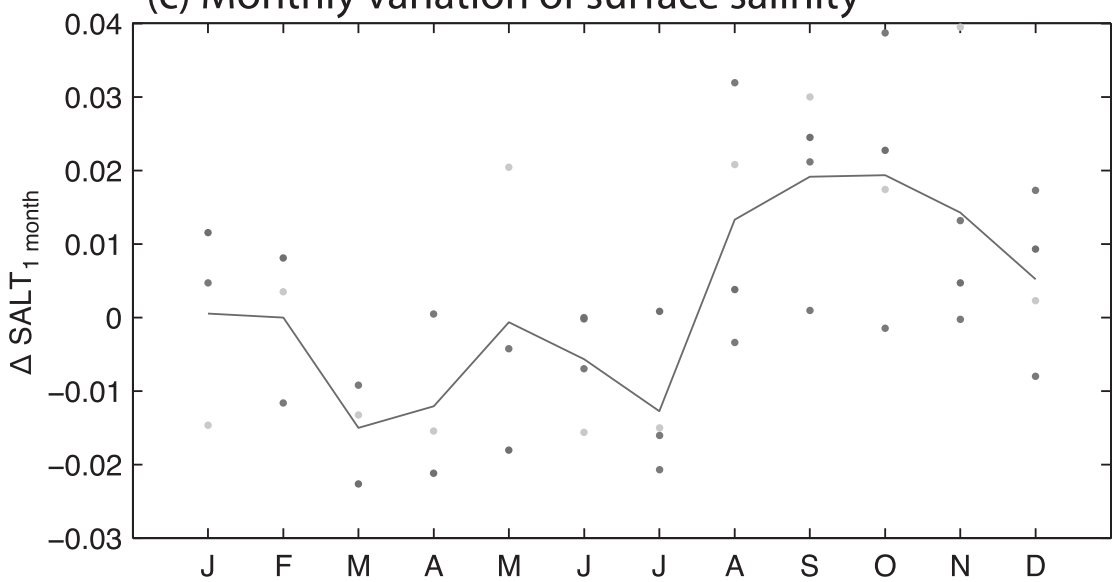

FIG. 6. (a) Salinity time series at station KERFIX between May 1991 and December 1994. Contours are every 0.03. (b) Time-mean standard deviation of salinity. (c) One-month lagged difference in surface salinity (in pss-78 units). See Park et al. (1998) for a full description of the KERFIX time series.

parameterization and $\lambda_{t}=30$ days. Signal and noise variances were taken as $0.02^{2}$ and $0.005^{2}$, respectively. The salinity offsets estimated by the cross-comparison method were found to be relatively insensitive to the choice of correlation radii, because the cross comparisons were carried out on surface salinity data obtained over a short time period and in a rather homogeneous area in terms of surface salinity.

A total of 503 CTD-SRDL profiles were available over the Northern Kerguelen Plateau, in the area of bottom depths ranging between 300 and $1000 \mathrm{~m}$. Before applying the cross-comparison method, a preprocessing of observations was performed. First, observations were resampled on $0.04^{\circ}$ latitude $\times 0.08^{\circ}$ longitude $\times 4$ days bins to avoid overweighting of dense patches of profiles during the least squares minimization. This process reduced the number of observations to 476 . Then, isolated observations were discarded, which were determined as ones having a covariance lower than $30 \%$ of the signal variance with any other observation. Finally, 309 observations were used during the analysis (see Table 3).

In the cross-comparison method, estimates of salinity offset are all given relative to a reference, taken as the salinity offset of a reference CTD-SRDL. The LCDW method gave an absolute estimate of salinity offsets for three seals that foraged sufficiently far south, which provided the needed salinity reference. The minimization has been done on two different subsets of CTDSRDLs, corresponding to the two different seasons of deployment (see Table 1). In the first set, we used CTDSRDL 10516 as a reference to estimate offsets for the four CTD-SRDLs: 10517, 10519, 10525, and 10526. CTDSRDL 10518 has not been included here because this 
TABLE 3. Results of the two surface salinity cross-comparison experiments. The number, mean, and standard deviation of surface salinity measurements are given for each CTD-SRDL, together with offset estimates. The standard deviation of offset differences (see appendix B for details of calculation) are given in the right panel.

\begin{tabular}{|c|c|c|c|c|c|c|c|c|c|c|}
\hline SRDL & $N$ & Mean $\left(S_{o}\right)$ & Std dev $\left(S_{o}\right)$ & $B_{s}-B_{\text {ref }}$ & $B_{s}$ & \multicolumn{5}{|c|}{$\operatorname{Std} \operatorname{dev}\left(B_{s}^{\text {row }}-B_{s}^{\text {column }}\right)\left(\times 10^{-3}\right)$} \\
\hline \multicolumn{11}{|c|}{ Expt 1: ref $=10516, B_{\text {ref }}=0$} \\
\hline 10516 & 98 & 33.92 & 0.015 & ref 1 & 0 & & 10516 & 10517 & 10519 & 10525 \\
\hline 10517 & 77 & 33.92 & 0.015 & 0.01 & 0.01 & 10517 & 1.8 & & & \\
\hline 10519 & 10 & 33.89 & 0.016 & -0.02 & -0.02 & 10519 & 7.2 & 7.4 & & \\
\hline 10525 & 13 & 33.92 & 0.036 & -0.01 & -0.01 & 10525 & 6.6 & 6.8 & 5.0 & \\
\hline 10526 & 90 & 34.07 & 0.011 & 0.16 & 0.16 & 10526 & 2.2 & 2.5 & 7.6 & 6.9 \\
\hline \multicolumn{11}{|c|}{ Expt 2: ref $=10535, B_{\text {ref }}=-0.07$} \\
\hline 10527 & 4 & 33.84 & 0.018 & -0.01 & -0.08 & & 10527 & 10528 & 10529 & \\
\hline 10528 & 4 & 33.79 & 0.003 & -0.05 & -0.12 & 10528 & 12.5 & & & \\
\hline 10529 & 4 & 33.84 & 0.005 & 0 & -0.07 & 10529 & 12.1 & 11.1 & & \\
\hline 10535 & 9 & 33.84 & 0.012 & ref 2 & -0.07 & 10535 & 11.0 & 8.2 & 9.8 & \\
\hline
\end{tabular}

seal did not cross over the Northern Kerguelen Plateau at this time. The second set corresponds to the four CTDSRDLs deployed later on in 2007 (between May and July). Here we used CTD-SRDL 10535 as the reference. The numerical results are summarized in Table 3.

The minimization method significantly reduced the differences between surface salinity observations available over the Northern Kerguelen Plateau, with the standard deviation of surface salinity observations lowered from 0.081 before the offset correction to only 0.015 afterward. Some CTD-SRDLs had small offsets, which could easily be neglected. However, others presented large offsets, which need to be corrected. The worst case was CTD-SRDL 10526, with an offset of 0.16. Several CTD-SRDLs showed rather large negative offsets of the order of -0.1 .

The standard deviation of offset differences for each couple of floats was also presented in Table 3. These standard deviations depended on both the number of profiles and how intertwined the locations and times of each pair of floats were, as defined by the covariance model used in the cross-comparison method. They varied from 0.002 to 0.012 , meaning the estimated offset difference is more or less robust. The accuracy of salinity offset estimate using the cross-comparison method depends on the uncertainties of both the salinity offset estimate of the reference CTD-SRDL $(\sim 0.02)$ and the estimated offset difference $(\sim 0.01)$. Finally, we estimated the accuracy of salinity measurements corrected using the cross-comparison method to \pm 0.03 .

\section{c. Visual comparisons of $T / S$ diagrams}

To verify the consistency of the estimation of salinity offsets obtained by both LCDW and the cross-comparison methods, visual comparisons of selected $T / S$ profiles have been undertaken. A reference database of historical profiles has been assembled, including all of the available profiles from oceanographic cruises and Argo profiles.
Areas where both CTD-SRDL and historical profiles were available were sought, and visual comparisons of $T / S$ diagrams were used to validate and homogenize the final seal dataset. The goal here was to check data against residual salinity offsets. Two examples of such visual comparisons are presented below.

In the first example, we compared the CTD-SRDLs 10516, 10517, and 10526 over the Northern Kerguelen Plateau in the area around $51^{\circ} \mathrm{S}, 75^{\circ} \mathrm{E}$, where a large number of nearby profiles were available. The standard deviations of their offset differences were very low $(<0.024$, see Table 3$)$, meaning that offset estimates are robust. A selection of profiles from these three SRDLs together with an historical profile is presented in Fig. 7. After the correction, the surface properties are more homogeneous, as would be expected. This figure also shows how it would be difficult to estimate salinity offset using deeper $T / S$ properties, because they are not always overlapping.

In the second example, three visual comparisons between nearby profiles of CTD-SRDLs 10525, 10528, and 10535 are presented (Fig. 8). These comparisons are done in three different areas where seal tracks intersected. By applying the offset corrections, we can see improved overlap of $T / S$ diagrams from the different CTD-SRDLs, especially when looking at the right-hand tails of $T / S$ curves corresponding to deeper water masses. In this example, the three areas where $T / S$ diagrams are compared are not situated over the Northern Kerguelen Plateau, indicating that the salinity offsets deduced from the crosscomparison methods do improve the accuracy of salinity measurements of CTD-SRDLs elsewhere, as we hoped.

\section{Discussion and conclusions}

In this paper, we have presented approaches to the delayed-mode calibration of a hydrographic dataset obtained with 10 CTD-SRDLs deployed on Kerguelen 
(a) No offset correction

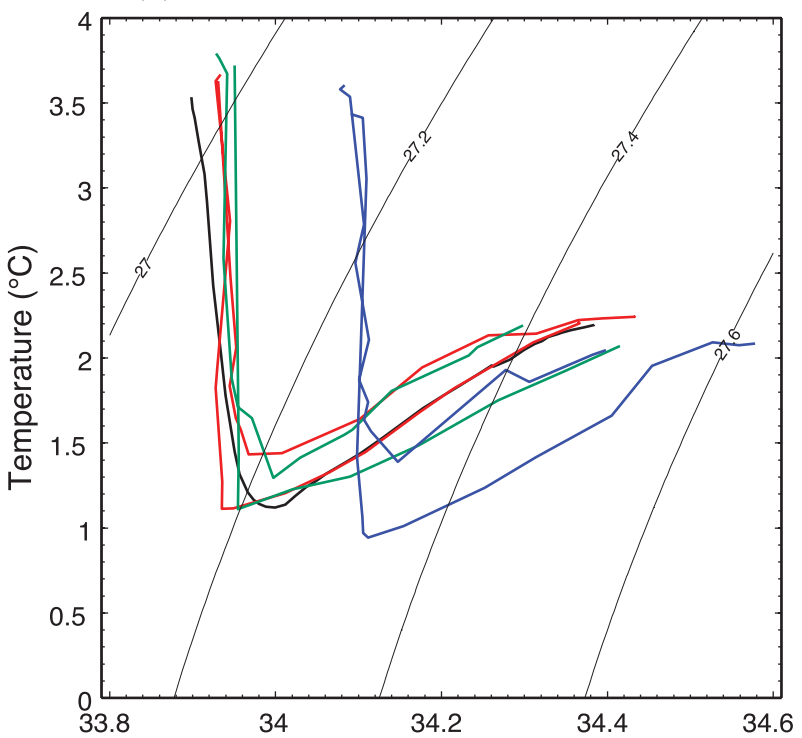

(b) Offset-corrected

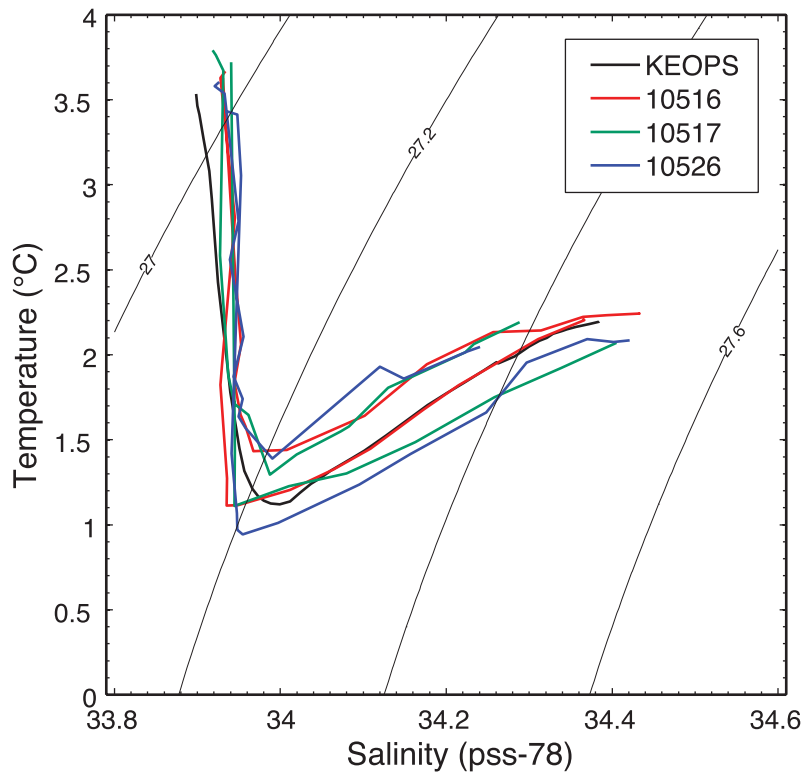

FIG. 7. Superposition of a selection of $T / S$ diagrams taken in the same area $\left(51^{\circ} \mathrm{S}, 75^{\circ} \mathrm{E}\right)$ from CTD-SRDLs 10516 (red), 10517 (green), and 10526 (blue). A close historical profile from the KEOPS cruise (see Park et al. 2008) is also overlaid (black). The profiles are shown (a) before and (b) after the salinity offset correction.

elephant seals in 2007. Two important steps were shown to be necessary to achieve the best possible accuracy. First, a ship-based CTD comparison was performed based on an at-sea experiment done prior to the deployment on elephant seals. These tests provided important indications of the overall quality of CTD-SRD sensors under actual field conditions. They revealed the existence of two main sources of systematic biases related to pressure effects and external field effects. If these biases were not corrected, then the accuracy was around $\pm 0.02^{\circ} \mathrm{C}$ for temperature and \pm 0.1 for derived salinity. However, a proper correction of observed biases had the potential to increase the accuracy to better than $\pm 0.01^{\circ} \mathrm{C}$ in temperature and \pm 0.01 in derived salinity.

Using the ship-based CTD comparisons, the pressure effect could be satisfactorily corrected on temperature measurements. The correction of salinity measurements was more complicated because the magnitude of the external field effect was modified when CTD-SRDLs were attached to the elephant seal head. The salinity correction was also linear with pressure, with the slope determined from the ship-based CTD comparisons, and the offset estimated using delayed-mode approaches. Two different delayed-mode approaches were presented. In the LCDW method we used the existence of a deep salinity maximum to reference CTD-SRDL salinity measurements. This method could only be used when this salinity maximum was actually sampled by the animal, that is, for elephant seals that foraged sufficiently far south (3 out of 10 animals). For the other CTD-SRDLs, a statistical cross-comparison method was employed, based on a weighted least squares minimization of surface salinity differences over the Northern Kerguelen Plateau.

The ship-based CTD comparisons also showed that the accuracy of hydrographic data will diminish above stratified regions with high rates of change of temperature with depth because time lag and thermal cell effects will increase there. We hypothesized that this effect should remain minor in the weakly stratified Southern Ocean, yet the magnitude of these effects remain poorly known and should be further tested in the future.

Finally, a calibrated seal dataset was produced with an accuracy of $\pm 0.01^{\circ} \mathrm{C}$ in temperature and derived salinity accuracy depending on the delayed-mode method used to estimate the salinity offset. An accuracy of \pm 0.02 could be achieved with the LCDW method. The crosscomparison method provided a somewhat poorer accuracy of about \pm 0.03 . Nicholls et al. (2008) reported similar estimates of accuracies $\left( \pm 0.005^{\circ} \mathrm{C}\right.$ in temperature and \pm 0.02 in salinity) obtained from ship-based CTD comparisons on three CTD-SRDLs deployed in the Weddell Sea. Although Roquet et al. (2009) performed ship-based CTD comparisons combined with the LCDW method, they found significantly lower accuracies of $\pm 0.03^{\circ} \mathrm{C}$ in temperature and \pm 0.05 in salinity, because they used an early version of CTD-SRDL that was more sensitive to pressure changes. The version of CTD-SRDL presented in this study has a better accuracy because the shape of the temperature probes was optimized and a pressure housing in titanium was added around the conductivity sensor. 
(a)

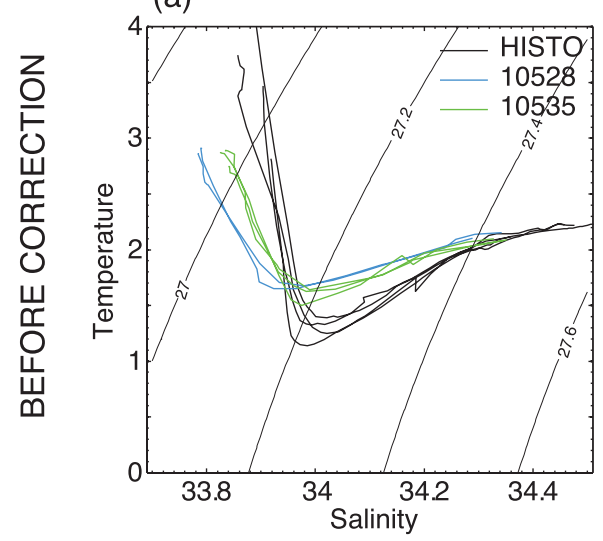

(d)

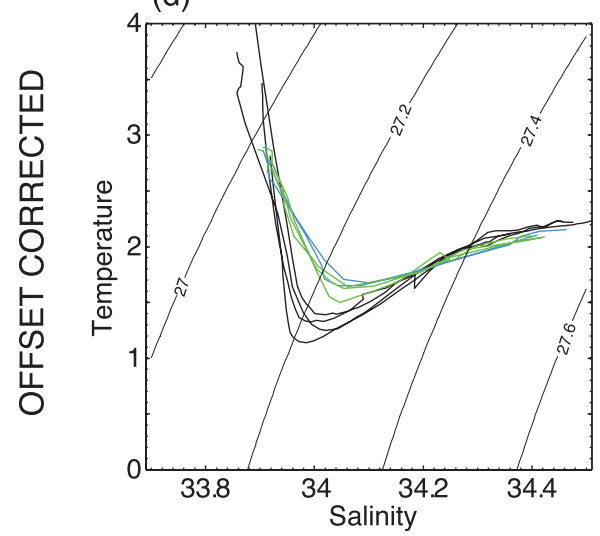

(b)

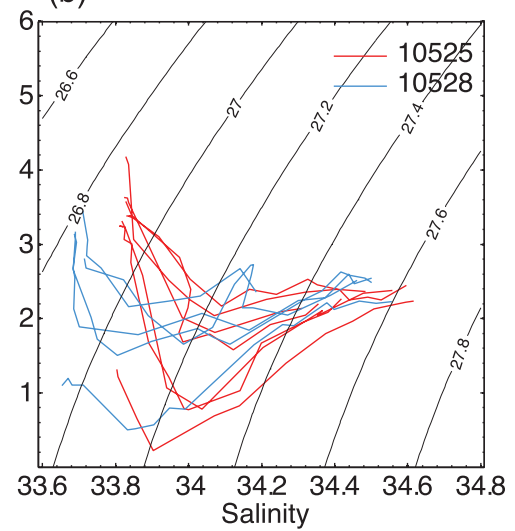

(e)

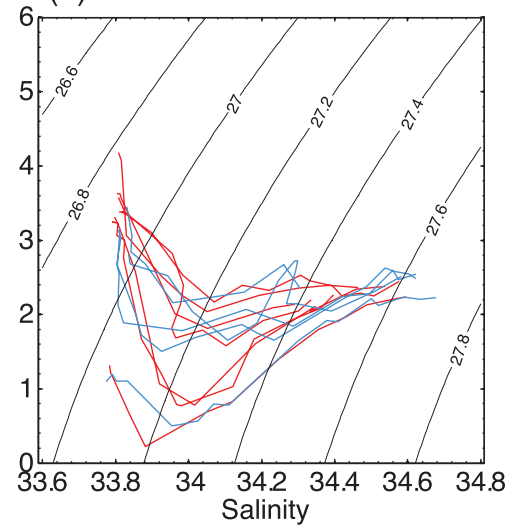

(c)

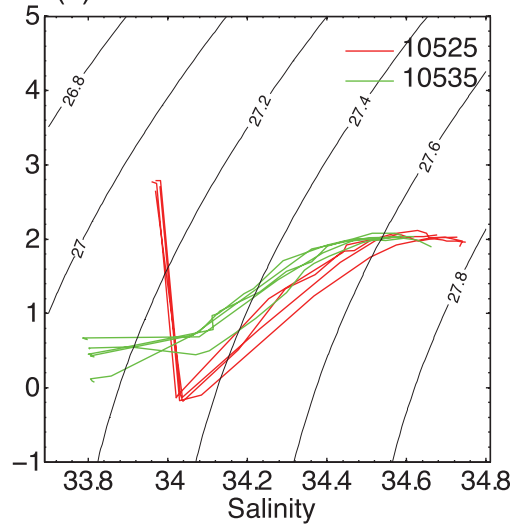

(f)

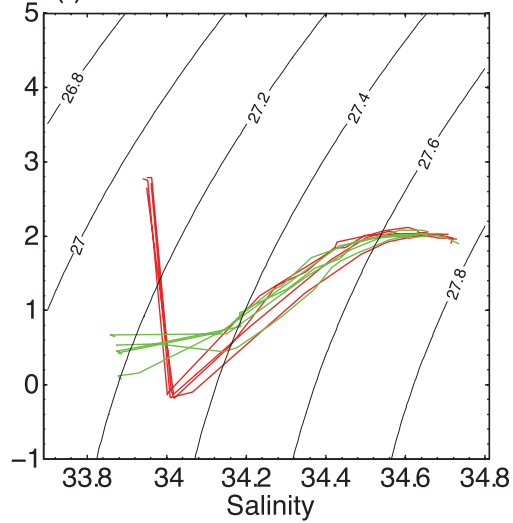

FIG. 8. Comparisons of close $T / S$ diagrams from CTD-SRDLs 10525, 10528, and 10535 in 3 different locations. In each cases, and although these comparisons are done far from the Northern Kerguelen Plateau, the $T / S$ diagram overlapping is improved after the offset correction.

In general, many CTD-SRDLs are deployed without undergoing ship-based CTD comparisons prior to deployment. Although the full calibration procedure presented here cannot be applied, it is still possible to correct the salinity offset using delayed-mode approaches. Based on ship-based CTD comparisons presented in this paper, we estimate that the accuracy of CTD-SRDL temperature measurements would be about $\pm 0.02^{\circ} \mathrm{C}$. For salinity measurements, the delayed-mode approaches would provide a lower accuracy, between 0.03 and 0.04 , depending on the quality of the salinity offset estimation, with a possible vertical dependency of the offset resulting from the noncorrected pressure effect. These accuracies would still be suitable for many oceanographic applications, so we recommend always estimating and correcting salinity offset.

We have presented a delayed-mode calibration procedure for a rather small elephant seal dataset. However, a similar procedure should be applied on any hydrographic dataset obtained using a CTD-SRDL. This paper also provided estimates of accuracies that are thought to be typical of most CTD-SRDLs from the latest generation produced since 2007. Because the use of animalborne CTD-SRDLs is rapidly increasing, the approaches proposed here to postprocess CTD-SRDL data should have increasing utility.

Acknowledgments. The present study is a contribution to the Southern Elephant Seals as Oceanographic Samplers (SEaOS) international program. Support for the development of the CTD-SRDL technology came from the U.S. Office of Naval Research's National Oceanographic Partnership Program and from the Natural Environment Research Council of the United Kingdom. The French component of SEaOS has been supported by CNES, along with IPEV and GMMC. We are very grateful to David Antoine for giving us access to the R/V Tethys II. Nicolas Brunel greatly helped to develop the statistical cross-comparison method. We also thank two anonymous reviewers for their constructive comments that greatly helped to improve the present manuscript. 


\section{APPENDIX A}

\section{Salinity Model for the External Field Effect}

The external field effect introduces a multiplicative factor on conductivity measurements (e.g., Fougere 2000) as

$$
\delta C=C_{\mathrm{SRDL}}-C=k C .
$$

A scale analysis of the factor $k$ can be undertaken using the Mediterranean experiment. For $C \simeq 45 \mathrm{mS} \mathrm{cm}^{-1}$ and $|\delta C| \simeq 0.1 \mathrm{mS} \mathrm{cm}^{-1}$, we obtain $|k|=\delta C / C \simeq 0.002 \ll 1$. The salinity bias $\delta S$ induced by the external field effect is $\delta S=\delta C(\partial S / \partial C)_{T}=k C(\partial S / \partial C)_{T}$. Because variations of $\mathrm{C} \cdot(\partial S / \partial C)_{T}$ are generally negligible $(<5 \%$ in the 2007 elephant seal dataset), the external field effect can be accurately modeled as an additive offset on salinity measurements.

\section{APPENDIX B}

\section{Least Squares Cross-Comparison Method}

Let us consider a set of $N$ salinity observations distributed over $M$ loggers. Each observation $S_{i}, i \in\{1 \ldots N\}$ is associated with the logger $f=F(i) \in\{1 \ldots M\}$. An estimate of the salinity offset $B_{s}^{f}$ is sought for each logger. The covariance between two observations $\left(S_{i}, S_{j}\right)$ is parameterized as

$$
c_{i, j}=\left(\left\langle s^{2}\right\rangle+K_{i, j}\left\langle n^{2}\right\rangle\right) \exp ^{-\left(\delta_{x} / \lambda_{x}\right)^{2}-\left(\delta_{y} / \lambda_{y}\right)^{2}-\left(\delta_{t} / \lambda_{t}\right)^{2}},
$$

with $\left\langle s^{2}\right\rangle$ the signal variance; $\left\langle n^{2}\right\rangle$ the noise variance; $K_{i, j}$ the Kronecker function (equal to 1 if $i=j$ and 0 otherwise); $\delta_{x}, \delta_{y}$, and $\delta_{t}$ the differences in latitude, longitude, and time, respectively; and $\lambda_{x}, \lambda_{y}$, and $\lambda_{t}$ the associated correlation radii, respectively.

In our cross-comparison problem, the primary data points are differences between two given observations of salinity $D_{i, j}=S_{i}-S_{j}$. The covariance between two of these differences is given by

$$
\operatorname{cov}\left(D_{i, j}, D_{k, l}\right)=c_{i, k}+c_{j, l}-c_{i, l}-c_{j, k} .
$$

Because this relationship is linear, only $N-1$ of these differences are independent. Let us consider the vector of differences $\mathbf{d}=\left[D_{i, i_{0}}\right]_{i \neq i_{0}}$, where $i_{0}$ is an arbitrarily chosen observation associated with the $\operatorname{logger} f_{0}=F\left(i_{0}\right)$. The logger $f_{0}$ plays the role of a reference logger, with $B_{s}^{f_{0}}=0$ by definition.

The weighted least squares theory provides an optimal estimator for the offset vector $\mathbf{B}=\left[B_{s}^{f}\right]_{f \neq f_{0}}$ and its associated covariance matrix $\mathbf{C}=\left[C_{f_{1}, f_{2}}\right]=\operatorname{cov}(\mathbf{B})$ as

$$
\begin{aligned}
& \mathbf{B}=\left(\mathbf{X}^{\mathrm{T}} \mathbf{W} \mathbf{X}\right)^{-1} \mathbf{X}^{\mathrm{T}} \mathbf{W} \mathbf{d}, \\
& \mathbf{C}=\left(\mathbf{X}^{\mathrm{T}} \mathbf{W} \mathbf{X}\right)^{-1},
\end{aligned}
$$

with $\mathbf{X}=\left[\partial B_{s}^{F(i)} / \partial B_{s}^{f}\right]_{i \neq i_{0}, f \neq f_{0}}=\left[K_{F(i), f}\right]_{i \neq i_{0}, f \neq f_{0}}$ the matrix containing the $M-1$ partial derivatives of the $N-1$ differences, and $\mathbf{W}=\left[\operatorname{cov}\left(D_{i, i_{0}}, D_{j, i_{0}}\right)\right]^{-1}$ the inverse of the covariance matrix of differences.

For each pair of loggers $\left(f_{1}, f_{2}\right)$ other than $f_{0}$, the standard deviation of their offset difference is given as

$$
\operatorname{stdev}\left(B_{s}^{f_{1}}, B_{s}^{f_{2}}\right)=\sqrt{C_{f_{1}, f_{1}}+C_{f_{2}, f_{2}}-2 C_{f_{1}, f_{2}}} .
$$

Numerical instability during the matrix inversion step could arise if some observations are too weakly correlated with the others. The noise variance parameter $\left\langle n^{2}\right\rangle$ increases the trace of the covariance matrix, thus increasing the numerical stability during the inversion.

The standard deviation of the offset differences depends solely on the covariance model and the relative position in time and space of observations, and not on salinity values. They provide a measure of the proximity between two loggers in terms of their available observations, getting closer to zero with an increasing number of nearby observations. The standard deviation of offset differences can be used as a measure of the robustness of the estimated offset difference between pairs of loggers.

\section{REFERENCES}

Antoine, D., and Coauthors, 2006: BOUSSOLE: A joint CNRSINSU, ESA, CNES, and NASA ocean color calibration and validation activity. GSFC Tech. Rep. NASA/TM-2006-214147, 68 pp. [Available online at http://www.obs-vlfr.fr/LOV/OMT/ fichiers_PDF/Antoine_et_al._NASA_TM_boussole.pdf.]

Argos, 2011: Argos user's manual. Collecte Localisation Satellites Tech. Rep., 66 pp. [Available online at http://www.argossystem.org/documents/userarea/argos_manual_en.pdf.]

Bailleul, F., J.-B. Charrassin, P. Monestiez, F. Roquet, M. Biuw, and C. Guinet, 2007: Successful foraging zones of southern elephant seals from Kerguelen Islands in relation to oceanographic conditions. Philos. Trans. Roy. Soc. London, 362, 21692181.

Biuw, M., and Coauthors, 2007: Variations in behavior and condition of a Southern Ocean top predator in relation to in situ oceanographic conditions. Proc. Natl. Acad. Sci. USA, 104, $13705-13710$.

Boehme, L., and U. Send, 2005: Objective analyses of hydrographic data for referencing profiling float salinities in highly variable environments. Deep-Sea Res. II, 52, 651-664.

, M. P. Meredith, S. E. Thorpe, M. Biuw, and M. Fedak, 2008: The Antarctic Circumpolar Current frontal system in the South Atlantic: Monitoring using merged Argo and animal-borne 
sensor data. J. Geophys. Res., 113, C09012, doi:10.1029/ $2007 \mathrm{JC} 004647$.

— , P. Lovell, M. Biuw, F. Roquet, J. Nicholson, S. E. Thorpe, M. P. Meredith, and M. Fedak, 2009: Technical note: Animalborne CTD-satellite relay data loggers for real-time oceanographic data collection. Ocean Sci., 5, 685-695.

Bost, C.-A., C. Cotte, F. Bailleul, Y. Cherel, J.-B. Charrassin, C. Guinet, D. Ainley, and H. Weimerskirch, 2009: Importance of southern fronts for seabirds and sea mammals of the southern oceans. J. Mar. Syst., 78, 363-376.

Charrassin, J.-B., and Coauthors, 2008: Southern Ocean frontal structure and sea-ice formation rates revealed by elephant seals. Proc. Natl. Acad. Sci. USA, 105, $11634-11639$.

Costa, D. P., J. Klinck, E. E. Hofmann, M. Dinniman, and J. M. Burns, 2008: Upper ocean variability in west Antarctic peninsula continental shelf waters as measured using instrumented seals. Deep-Sea Res. II, 55, 323-337.

Durand, F., and G. Reverdin, 2005: A statistical method for correcting salinity observations from autonomous profiling floats: An Argo perspective. J. Atmos. Oceanic Technol., 22, 292-301.

Fedak, M., 2004: Marine animals as platforms for oceanographic sampling: A "win/win" situation for biology and operational oceanography. Mem. Nat. Inst. Polar Res., 58, 133-147.

— , P. Lovell, B. McConnell, and C. Hunter, 2002: Overcoming the constraints of long range radio telemetry from animals: Getting more useful data from smaller packages. Integr. Comp. Biol., 42, 3-10.

Fofonoff, P., and R. C. J. Millard, 1983: Algorithms for computation of fundamental properties of seawater. UNESCO Tech. Papers in Marine Science 44, 53 pp.

Fougere, A. J., 2000: New non-external field inductive conductivity sensor (NXIC) for long-term deployments in biologically active regions. OCEANS 2000 MTS/IEEE Conf. and Exhibition, Providence, RI, IEEE, 623-630.

Hindell, M. A., D. J. Slip, H. R. Burton, and M. M. Bryden, 1992: Physiological implications of continuous, prolonged and deep dives of the southern elephant seal (Mirounga leonine). Can. J. Zool., 70, 370-379.
Hooker, S. K., and I. L. Boyd, 2003: Salinity sensors on seals: Use of marine predators to carry CTD data loggers. Deep-Sea Res. I, 50, 927-939.

Lydersen, C., O. A. Nøst, P. Lovell, B. J. McConnell, T. Gammelsrød, C. Hunter, M. A. Fedak, and K. M. Kovacs, 2002: Salinity and temperature structure of a freezing Arctic fjord monitored by white whales (Delphinapterus leucas). Geophys. Res. Lett., 29, 2119, doi:10.1029/2002GL015462.

Nicholls, K. W., L. Boehme, M. Biuw, and M. A. Fedak, 2008: Wintertime ocean conditions over the southern Weddell Sea continental shelf, Antarctica. Geophys. Res. Lett., 35, L21605, doi:10.1029/2008GL035742.

Orsi, A. H., T. Whitworth III, and W. D. Nowlin, 1995: On the meridional extent and fronts of the Antarctic Circumpolar Current. Deep-Sea Res. I, 42, 641-673.

Park, Y.-H., E. Charriaud, D. Ruiz-Pino, and C. Jeandel, 1998: Seasonal and interannual variability of the mixed-layer properties and steric height at station KERFIX southwest of Kerguelen. J. Mar. Syst., 17, 233-247.

_ F. Roquet, I. Durand, and J.-L. Fuda, 2008: Large scale circulation over and around the northern Kerguelen Plateau. Deep-Sea Res. II, 55, 566-581.

—, F. Vivier, F. Roquet, and E. Kestenare, 2009: Direct observations of the ACC transport across the Kerguelen Plateau. Geophys. Res. Lett., 36, L18603, doi:10.1029/2009GL039617.

Rio, M.-H., and F. Hernandez, 2004: A mean dynamic topography computed over the world ocean from altimetry, in situ measurements, and a geoid model. J. Geophys. Res., 109, C12032, doi:10.1029/2003JC002226.

Roquet, F., Y.-H. Park, C. Guinet, F. Bailleul, and J.-B. Charrassin, 2009: Observations of the Fawn Trough Current over the Kerguelen Plateau from instrumented elephant seals. J. Mar. Syst., 78, 377-393.

Vincent, C., B. McConnell, V. Ridoux, and M. Fedak, 2002: Assessment of Argos location accuracy from satellite tags deployed on captive gray seals. Mar. Mammal Sci., 18, 156-166.

Wong, A. P. S., G. C. Johnson, and W. B. Owens, 2003: Delayed-mode calibration of autonomous CTD profiling float salinity data by @-S climatology. J. Atmos. Oceanic Technol., 20, 308-318. 